\title{
IN VITRO FERTILIZATION (IVF) CENTRE AT DHAKA MEDICAL COLLEGE HOSPITAL - A NEW HOPE FOR INFERTILE COUPLE!
}

One of the basic needs of all human being is the need to have children.

The desire of women is usually stronger than self -interest in beauty and figure and may be stronger than the clam of a carrer. In man it is usually less intense. ${ }^{1}$

Normal fertility is usually depened as achieving a pregnancy within 2 years by regular coital exposure. It is estimated that about $90 \%$ of couples will achieve pregnancy in the first year and $95 \%$ in $2^{\text {nd }}$ year. ${ }^{2}$

Infertility means not being able to become pregnant after a year of unprotected sexual intercourse. It affects approximately 13\% among women and $10 \%$ among men. ${ }^{3}$ One of the 4 couple in developing country had been found to be affected by infertility. ${ }^{4}$

Infertility remains a neglected issue in Bangladesh reproductive health policy; instead, the emphasis has always been on the problem of overpopulation. As a result the dominant state ideology in Bangladesh is related to controlling fertility, and the implementation of family planning programmes has become a success story for the country. ${ }^{5}$ Although no epidemiological study has been conducted in the national level to known the prevalence rate of infertility in Bangladesh, a global review of infertility from the World Fertility Survey and others estimated infertility rates in South Asia Countries stated $4 \%$ in Bangladesh. Another estimate of overall primary and secondary infertility in South Asia, on the basis of women at the end of their reproductive lives in the age group 45-49 years, suggests an infertility rate of approximately $15 \%$ in Bangladesh. Which is the highest among all South Asia countries. 6,7

It is a common and severe health problem which not only affects one's ability to have children, but also has emotional, economical, psychological, family and social effects. ${ }^{8}$
Infertility affects both men and women. Yet women particularly in developing country, may bear the sole blame for barren marriages. In many areas infertility is a socially acceptable basis for divorce by the husband. 9,10

Rural childless women experience social isolation, strong stigma, feelings of guilt, role failure, loss of self esteem, abandonment by the family rather than Urban childless women. Poverty, tuberculosis malnutrition, anaemia and reproductive tract infection are the main risk factor of infertility here. Sexually transmitted disease (STD), late marriage, improper medication and general hygienic condition, random use of oral contraceptive for long time are the causes of human infertility in Bangladesh. The treatment of infertility is not available in local hospitals due to the lack of specialist. ${ }^{11}$

The announcement of the birth of Louisa Brown in July 1978 was not the begining of the end of In Vitro fertilization (IVF), but an important milestone along the way to what is now an important and internationally recognised treatment option for some infertile couples. ${ }^{2}$

It is unbelievable, that how much the field of reproductive medicine has grown and matured over the past five to six decades. In each year IVF cycle increases steadily over the years and since the first IVF baby was born.

ART is very sophisticated and costly treatment and few private centres were available in Bangladesh but still it is beyond the reach of general people. Due to its high cost \& only 30$40 \%$ success rate most of the infertile couple remain frustrated.

Dhaka medical college hospital is a largest tertiary level hospital in Bangladesh, Huge number of Gynae patient attend every day in OPD but special attention to infertile couples were not possible

Correspondence: Prof. Nilufar Sultana, Professor \& Head, Department of Obstetric \& Gynaecology, Dhaka Medical College, Dhaka. E-mail: 
due to overload. So, people get frustrated day by day as they unable to sick private consultation because of high cost. Considering this situation we have started separate infertility OPD, inpatient services \& all types of fertility conserving surgery including laparoscopy $\&$ hysteroscopy since 2015. Intrauterine insemination (IUI) is one of the ART procedure also started at the end of 2016. We provide all services free of cost and success rate is comparable with other private centers. After then decision was taken to established an ART (test tube baby) laboratory for all types of advanced reproductive technology. Recently we have completed ART Lab. at DMCH with all the facilities like IVF, ICSI,TESA,PESA, cryopreservation, frozen embryo transfer $\&$ other facilities include hormon analysis \& transvaginal scan (TVS) with very minimum cost. This is the $1^{\text {st }}$ ART Lab. in Govt-hospital of Bangladesh. Hope, we will start our services within very short period of time for mostly poor, neglected, frustrated infertile couples. Our target, every couple should have a family.

Welcome to ART Lab at DMCH. Stay safe \& blessed always.

J Dhaka Med Coll. 2019; 28(2) : 129-130

\section{Prof. Nilufar Sultana}

Professor \& Head, Department of Obstetric \& Gynaecology, Dhaka Medical College, Dhaka

\section{References:}

1. Infertility and Associated Reproductive Technology, principles of Gynaecology $7^{\text {th }}$ edition Chapter40: page-699.

2. Peter R. Brinsden, An Introduction to Bourn Hall, A text book of In Vitro Fertilization and Assisted Reproduction. Second edition. Page-5

3. RL Barbieri - Yen and Jaffes Reproductive Endocrinology, 2019- Elsevier

4. Global prevalence of infertility, infecundity and childlessness- WHO

5. Ahmed \& Chowdhury, 1999; Country Report, 2006

6. Vassen M (1984) infecundity WFS Comparative studies. Series 31 . Voorburg. The Netherlands: cross national Summaries

7. Kumar D (2007) Prevalence of female infertility and its Socioeconomic factors in Tribal communities of Central India. Rural Remote Health 7:456

8. Douglas Te (2007) the genetics of male infertility. Humana Press rnc. Suite 208 To towa, New Jersey 07512, ISBNI - 58829-863-869

9. Singh AJ (1996) Support for infertile couple World Health Forum 17:176-177

10. Yeboah ED. Wadhwani JM, Wilson JB (1992) Etiological factors of male infertility in Africa. Int. J Fertil 37:300-307

11. Review Article iMed Pub Journals http:// www imedpub.com 